\title{
Identification of differentially expressed genes and pathways for intramuscular fat metabolism between breast and thigh tissues of chickens
}

\author{
Huanxian Cui ${ }^{1,2+}$, Maiqing Zheng ${ }^{1,2+}$, Guiping Zhao ${ }^{1,2}$, Ranran Liu ${ }^{1,2}$ and Jie Wen ${ }^{1,2^{*}}$ (D)
}

\begin{abstract}
Background: Intramuscular fat (IMF) is one of the important factors influencing meat quality, however, for chickens, the molecular regulatory mechanisms underlying this trait have not yet been clear. In this study, a systematic identification of differentially expressed genes (DEGs) and molecular regulatory mechanism related to IMF metabolism between Beijing-you chicken breast and thigh at 42 and 90 days of age was performed.

Results: IMF contents, Gene Ontology (GO) terms, and Kyoto Encyclopedia of Genes and Genomes (KEGG) pathways were analyzed, The results showed that both IMF contents in breast at 42 and $90 \mathrm{~d}$ were significantly lower $(P<0.05$ or $P<0.01)$ than those in thigh. By microarray, 515 common known DEGs and 36 DEGs related to IMF metabolism were identified between the breast and thigh at 42 and $90 \mathrm{~d}$. Compared to thigh, the expression levels of PPARG had significantly down-regulated $(P<0.01)$ in breast, but the expression levels of RXRA and CEBPB had significantly up-regulated $(P<0.01)$. However, the expression levels of $L P L, F A B P 4, T H R S P, R B P 7, \angle D L R, F A B P 3, C P T 2$ and PPARGC1A had significantly down-regulated in breast $(P<0.01)$, supporting that $P$ PARG and its down-stream genes had the important regulatory function to IMF deposition. In addition, based on of DEGs, KEGG analysis revealed that PPAR signaling pathway and cell junction-related pathways (focal adhesion and ECM-receptor interaction, which play a prominent role in maintaining the integrity of tissues), might contribute to the IMF metabolism in chicken.

Conclusions: Our data had screened the potential candidate genes associated with chicken IMF metabolism, and imply that IMF metabolism in chicken is regulated and mediated not only by related functional genes and PPAR pathway, but also by others involved in cell junctions. These findings establish the groundwork and provide new clues for deciphering the molecular mechanisms underlying IMF deposition in poultry. Further studies at the translational and posttranslational level are now required to validate the genes and pathways identified here.
\end{abstract}

Keywords: Microarray, Differentially expressed gene, Regulatory mechanism, Intramuscular fat, Breast and thigh, Chicken

\section{Background}

Intramuscular fat (IMF) represents deposited lipid in the muscle tissue, which is distributed in the epimysium, perimysium, and endomysium. The certain IMF content in the muscle tissues will not only improve the sensory quality of the meat, but also enhance its flavor, tenderness, and water retention [1-4]. Lipid biosynthesis in chickens

\footnotetext{
* Correspondence: Jiewen@iascaas.net.cn

${ }^{\dagger}$ Equal contributors

'Institute of Animal Sciences, Chinese Academy of Agricultural Sciences,

Beijing 100193, China

${ }^{2}$ State Key Laboratory of Animal Nutrition, Beijing 100193, China
}

mainly occurs in the liver, which is different from pigs, in which lipids are mainly synthesized in the adipose tissue [5]. After synthesis, lipids, in the form of lipoproteins, are transported via blood circulation to target tissues, where the lipoproteins are hydrolyzed by lipoprotein lipase and fatty acids are released for immediate use or deposition [6]. The IMF content depends on the number of adipocytes and the capacity for lipid deposition. The number of adipocytes is decided before birth, and the lipid deposition capability of adipocytes is affected by various factors after birth. Thus, the adipocyte number of an animal is decided 
prenatally and the deposition of lipids would be completed by increasing the adipocyte volume and weight during subsequent growth [7].

In our previous studies, IMF deposition in thigh was observed to be significantly higher than in breast muscle [8]. IMF deposition is a dynamic process that is regulated comprehensively by hormones and cell factors, including a series of steps such as adipocyte differentiation, and the synthesis, transportation, and decomposition of lipids. The regulation of lipid metabolism is extremely complex because of the interactions of these factors.

In the current work, many studies on the regulation of single gene to IMF had been finished, but few studies on the molecular regulation mechanism of IMF in chickens were performed. In the present study, we used Beijing-you (BJY) chickens, which is a local breed with a rich IMF content, and the Agilent chicken genome array to systematically identify differentially expressed genes (DEGs) related to IMF and explore the molecular regulatory mechanism of IMF through the comparison between breast and thigh tissues at 42 and 90 days of age.

\section{Results}

\section{Differences in IMF between breast and thigh tissues}

The IMF contents in breast and thigh tissues at 42 and $90 \mathrm{~d}$ were detected, respectively. The IMF content in thigh tissue $(2.43 \%)$ was significantly higher $(P<0.05)$ compared with that in breast tissue $(3.76 \%)$ at 42 day of age. Similarly, the IMF content in thigh tissue (2.74\%) was significantly higher $(P<0.01)$ compared with that in breast tissue (5.39\%) at 90 day of age (Fig. 1).

\section{The validation of the microarray and identification of DEGs related to IMF metabolism}

Firstly, total RNA were detected to ensure the quality for microarray, and the results showed that the quality of obtained total RNA was satisfying, and could meet

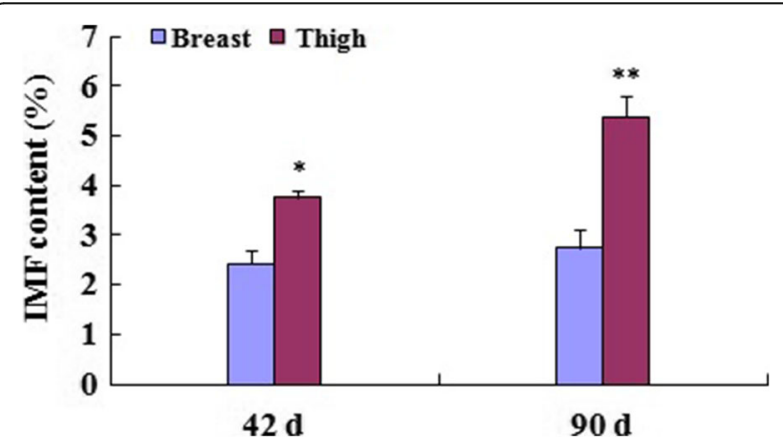

Fig. 1 IMF contents in breast and thigh tissues at 42 and $90 \mathrm{~d}$. The IMF contents in thigh were significantly higher $(P<0.05, P<0.01$, respectively) compared with those in breast at 42 and $90 \mathrm{~d}$. Data are the means $\pm S D, n=12$ the experimental requirements (Fig. 2). The breast was used as the control, and comparisons between the thigh and breast at $42 \mathrm{~d}$ and 90 day of age were respectively performed (42BB vs $42 \mathrm{BT}$, and $90 \mathrm{BB}$ vs $90 \mathrm{BT}$ ), respectively. To validate the reliability of the microarray data, the normal distribution analysis was performed in four microarrays, and data of each microarray was in accordance with normal distribution (Fig. 3a), which showed that the microarray data was reliable. The cluster analysis of all microarrays also was performed (Fig. 3b) using the Cluster 3.0 software. The results showed that data in the microarrays of 42 and $90 \mathrm{~d}$ within the same tissue were closely related, which also confirmed the reliability of the microarray data. For two comparisons, 515 known genes were detected as DEGs, 290 up-regulated and 225 down-regulated (Additional file 1).

\section{The identification of DEGs related to IMF metabolism}

Using the 515 known DEGs between the thigh and breast at 42 and $90 \mathrm{~d}, \mathrm{GO}$ analyses were performed, respectively. The common significantly enriched GO terms $(P<0.05)$ in the ontology "Biological Process" of the two comparisons were chosen, including muscle system process, lipid metabolic process, cell cycle, et al. (Additional file 2). On the basis of the enriched GO-terms and 515 common known DEGs, 42 DEGs related to lipid metabolism were screened. Combined with the changes in IMF contents in thigh and breast tissues at 42 and $90 \mathrm{~d}$, certain DEGs related to lipid metabolism were rejected, and the remaining 36 DEGs were considered as DEGs related to IMF metabolism in this study (Additional file 3).

Among them, some representative genes related to lipid metabolism were found, and the verifications of their mRNA levels by Q-PCR were performed (Fig. 4). Though the fold changes of PPARG were 2.45 and 1.92 (Additional file 3), it also was detected by Q-PCR for the importance in lipid metabolism. Compared to thigh, the expression levels of PPARG had significantly downregulated $(P<0.01)$ in breast. However, the expression of $R X R A$ and $C E B P B$, had significantly up-regulated $(P<$ $0.01)$, contradicting with previous reports. Meanwhile, the mRNA levels of KLF2 and PPARGC1A had significantly down-regulated $(P<0.01)$. However, as the target genes of PPARG, the expression levels of FABP4, LPL, CPT2 and $F A B P 3$ had significantly down-regulated in breast $(P<0.01)$. In addition, THRSP, RBP7 and $L D L R$, which accelerate the lipid biosynthesis, also had significantly downregulated in breast $(P<0.01)$.

To deeply confirm results from the microarrays, the fold changes of the above 12 genes in microarray and q-PCR were related using Spearman rank correlation. As shown in Fig. 5, fold-changes in gene expression between breast and thigh by two methods were correlated at $42 \mathrm{~d}$ $(r=0.9861, P<0.01)$ and $90 \mathrm{~d}(r=0.9534, P<0.01)$. This 

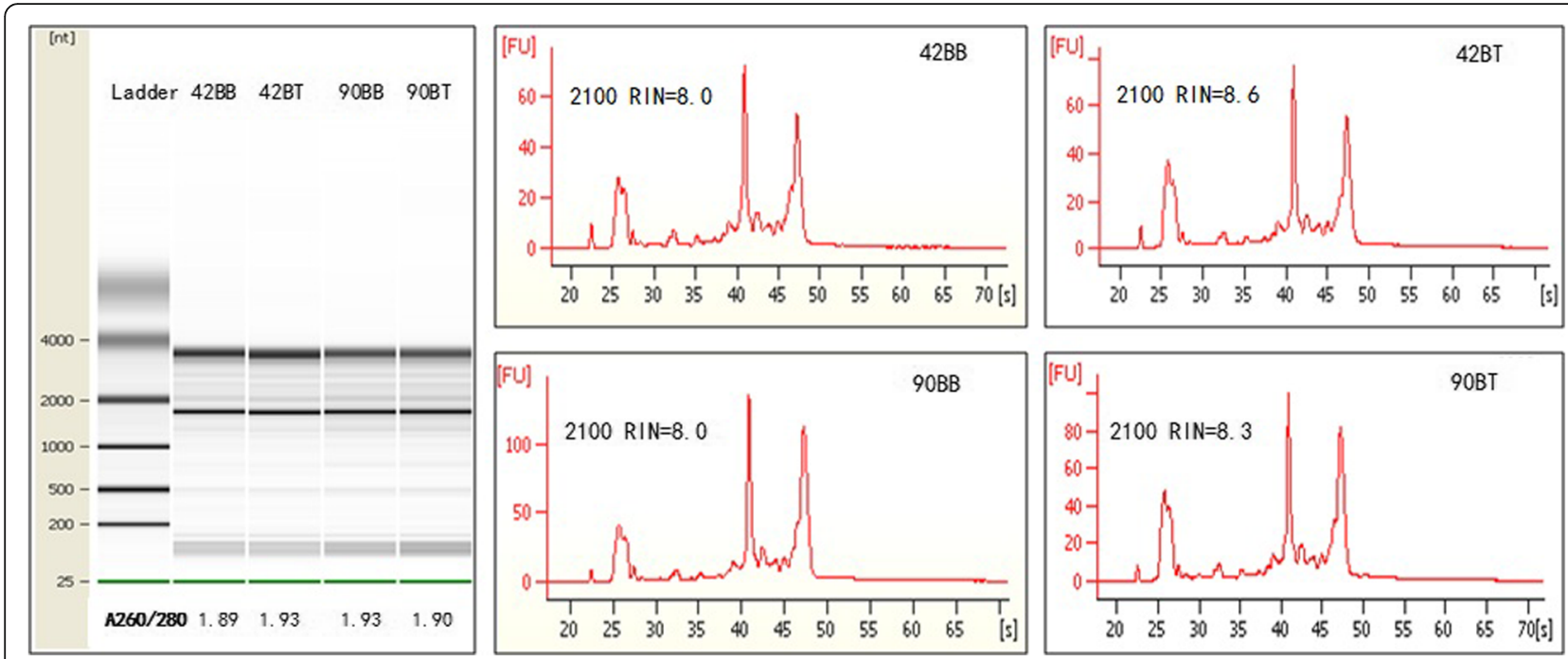

Fig. 2 Detection of RNA quality. The total RNAs were separate, their qualities were identified. The results of gel electrophoresis, the ratios of A260/A280 and 2100 RIN showed that the obtained total RNA had the higher acceptance for microarray

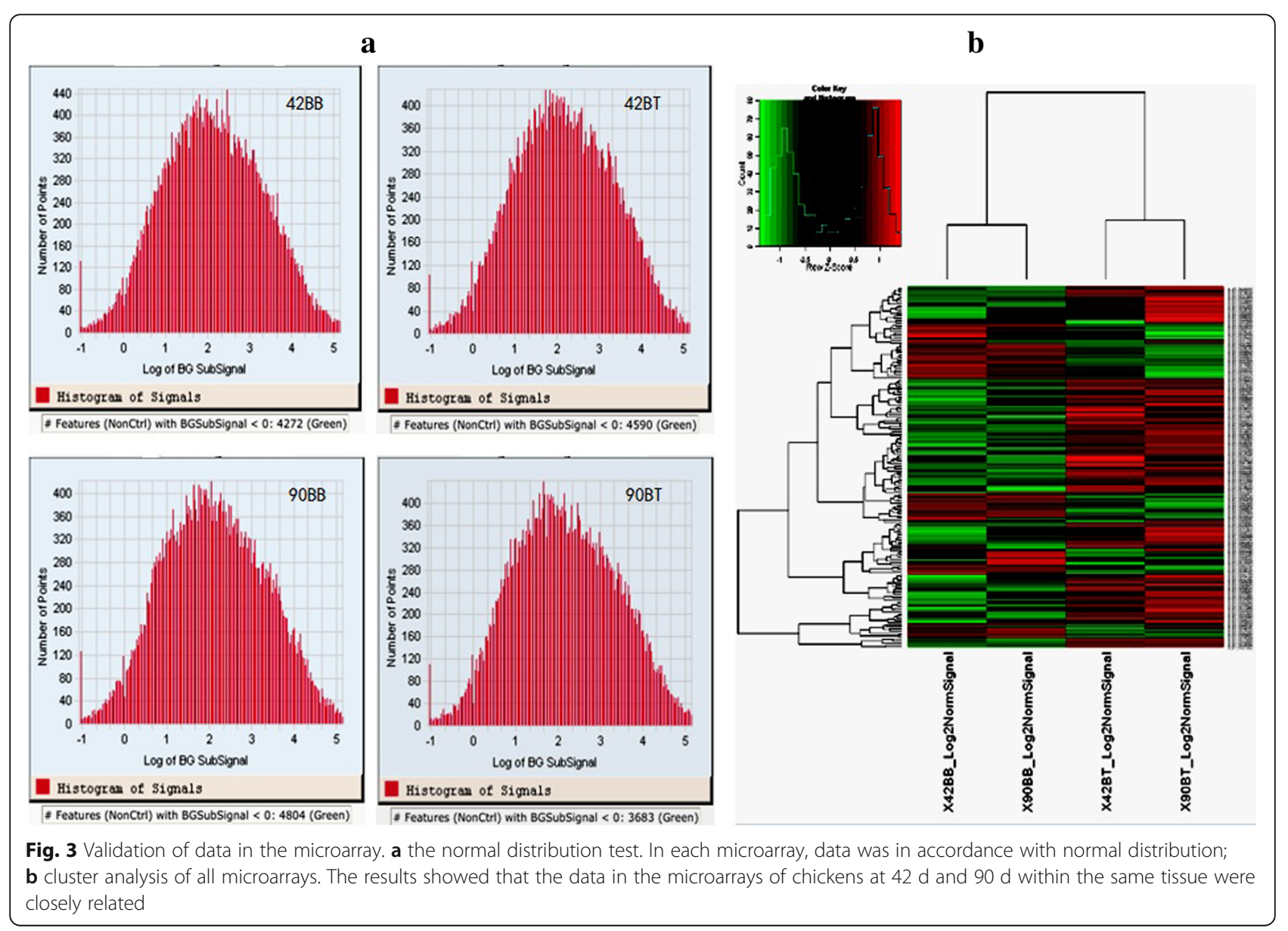




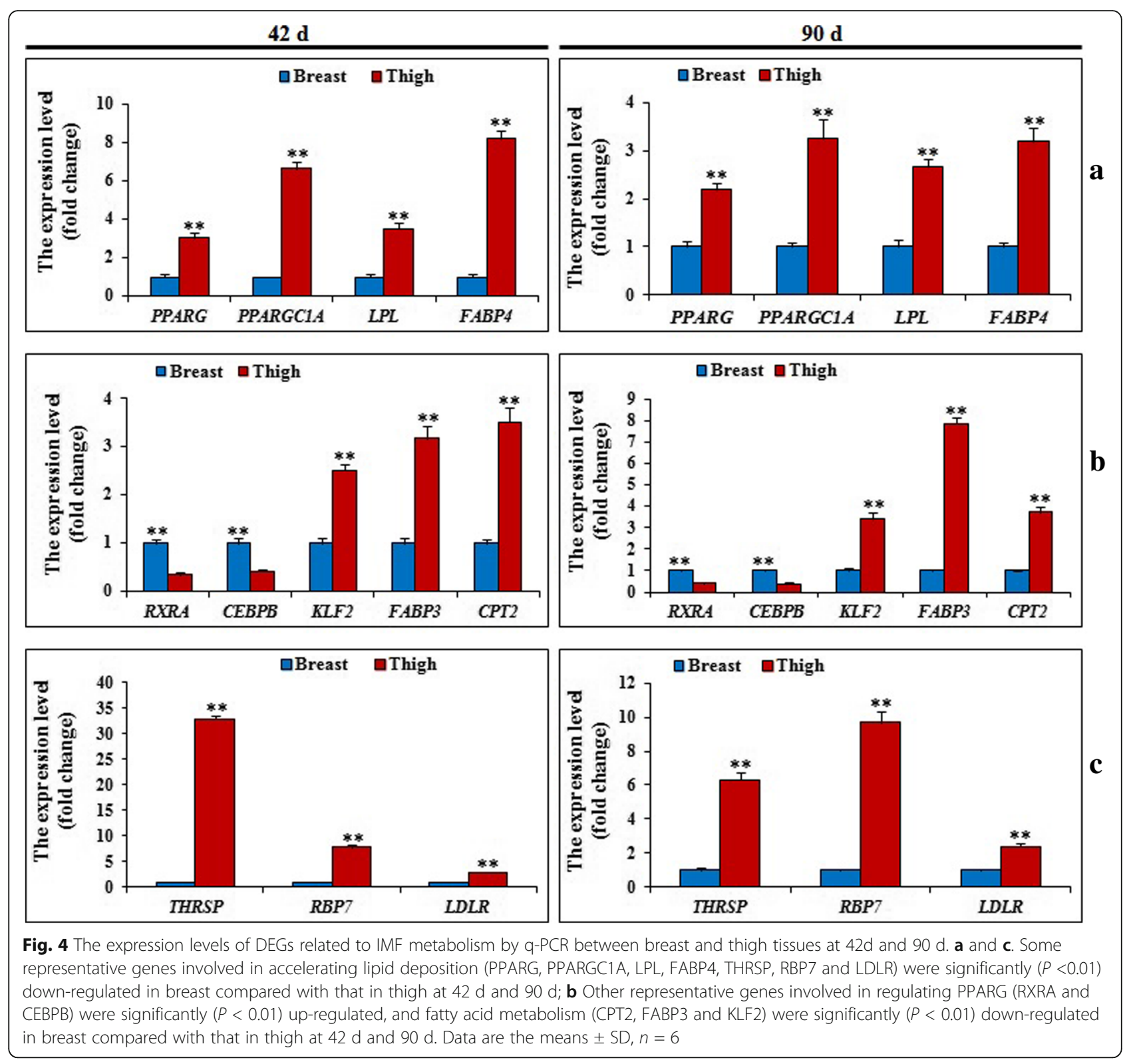

result also showed the consistency between the results of DEGs by q-PCR and the microarray analyses, and highly confirmed the reliability of the microarray data.

The analysis of pathways on IMF metabolism

KEGG pathway analysis for the 515 common known DEGs from the two comparisons was performed, and the enriched (q-value <0.05) KEGG pathways were screened (Table 1). As expected, PPAR signaling pathway were found, and other significant pathways included focal adhesion, ECM-receptor interaction, et al. The DEGs involved in these pathways were also screened, and 10, 18 and 9 DEGs were involved in the PPAR signaling pathway, focal adhesion and ECM-receptor interaction, respectively.

For two pathways (focal adhesion and ECM-receptor interaction), 5 commom DEGs (COL5A2, COL6A2, COL6A3, RELN and SPP1) were found (Additional file 4). In addition, the DEGs related to IMF metabolism were also respectively found in Focal adhesion $(C A V 1)$ and ECM-receptor interaction (CD36).

Overall consideration to the results of the IMF contents, DEGs related to lipid metabolism and the KEGG pathways in this study, we then constructed the hypothetical and potential regulatory mechanism for IMF metabolism using the biological and gene function information in NCBI Entrez (Fig. 6). 


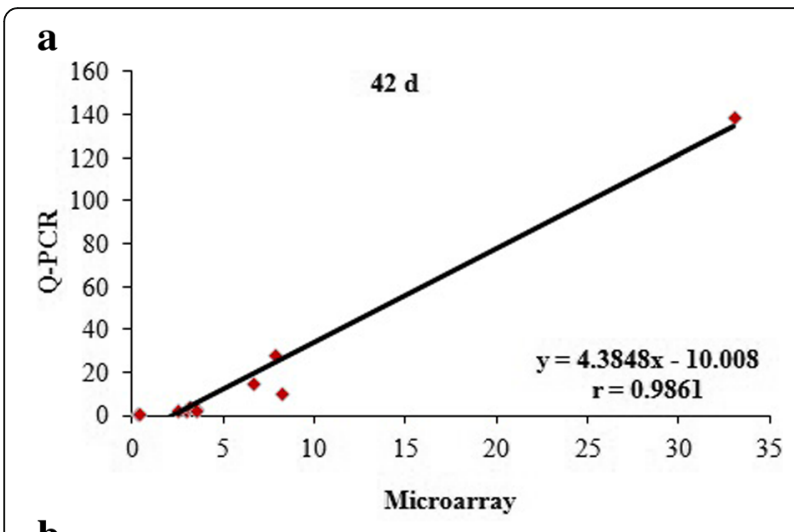

b

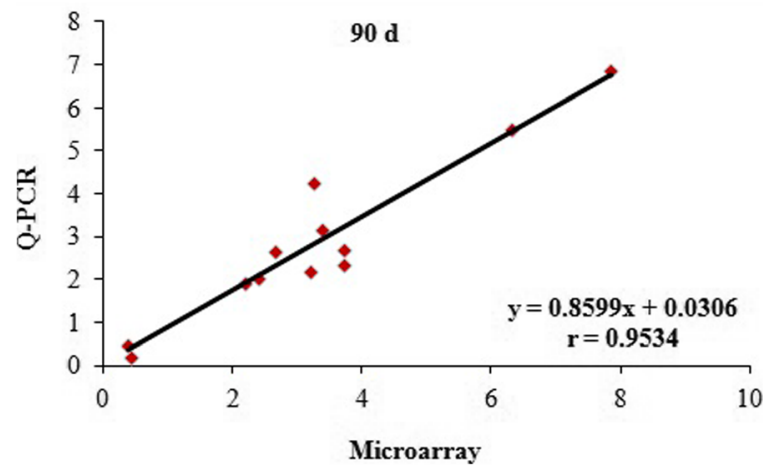

Fig. 5 Technical validation of microarray results using $q-P C R$ correlation. $\mathbf{a}$ and $\mathbf{b}$. The $r=0.9861$ (42 d, $P<0.01$ ) (a) and $r=0.9534$ (90 d,

$P<0.01)(\mathbf{b})$ indicate that the Spearman Rank Correlation between breast and thigh were positive. This indicated that the q-PCR fold changes were in complete correspondence with the microarray data in two days of age. Data are the means $\pm \mathrm{SD}, n=12$

\section{Discussion}

Deposited lipids in chickens include mainly abdominal fat, subcutaneous fat and IMF, and most studies have been performed on abdominal fat. The expressions of certain genes, involved in lipid deposition, have been analyzed in chickens [9-12]. Some research had been finished to systematically analyze the DEGs and regulatory mechanism in abdominal fat or IMF of breast using a cDNA microarray $[13,14]$. However, few studies have systematically analyzed the gene expression profiles related to IMF in breast and thigh of chickens. In this study, the present objective was to identify global genes

Table 1 The enriched $(P<0.05)$ KEGG pathways in microarray

\begin{tabular}{llll}
\hline Pathways & Hits & Total & $P$-value \\
\hline PPAR signaling pathway & 10 & 59 & 0.000972 \\
Focal adhesion & 18 & 184 & $5.11 \mathrm{E}-05$ \\
ECM-receptor interaction & 9 & 73 & 0.001877 \\
Valine. leucine and isoleucine degradation & 5 & 44 & 0.048259 \\
Propanoate metabolism & 5 & 25 & 0.007102 \\
Pyruvate metabolism & 6 & 34 & 0.008396 \\
\hline
\end{tabular}

and pathways affecting chicken IMF metabolism to explore the regulatory mechanism of IMF between breast and thigh tissues of BJY chickens at $42 \mathrm{~d}$ and $90 \mathrm{~d}$ by cDNA microarray.

\section{cDNA array analysis}

After obtained the high quality total RNA, chicken microarrays were employed, each using pooled RNA samples $(n=6$ birds, within each of two tissues and at 2 ages; 4 arrays in all). Such a pooling strategy can dramatically improve accuracy when only one array is available in each biological condition [15]. To validate the results from the microarray, a normal distribution test and cluster analysis of all microarrays were performed. In each microarray, data was in accord with the normal distribution test. Moreover, the cluster analysis showed a close relationship between the data of two microarrays at $42 \mathrm{~d}$ and $90 \mathrm{~d}$ among thigh tissue and breast tissue, respectively. This result correlated with the known physiological development of chickens and confirmed the reliability of the microarray data. In this study, 12 DEGs were selected from the 36 common DEGs related to IMF metabolism to deeply validate the results, more than 52 tests were done by q-PCR, and fold-changes in gene expression between the two methods were highly correlated at $42 \mathrm{~d}$ and $90 \mathrm{~d}$ in chickens. These results further confirmed the reliability of the microarray data.

\section{The genes related to lipid biosynthesis are responsible for IMF deposition}

According to GO-term analysis on basis of 515 common known DEGs, 36 DEGs related to IMF metabolism were shared by thigh and breast at 2 ages. Among them, PPARG plays an important role in regulating adipocyte differentiation and lipid deposition [16-18], PPARGC1A is a co-activator of PPARG $[19,20]$, and their expression had significantly down-regulated in breast $(P<0.01)$ compared to those in thigh at 42 and $90 \mathrm{~d}$. It was misleading that the mRNA levels of RXRA and CEBPB, as the cofactor of PPARG [21, 22], had significantly up-regulated in breast $(P<0.01)$. In addition, the expression of KLF2, which would negatively regulate PPARG expression [23], also had significantly decreased in breast $(P<0.01)$. However, as the targets of PPARG [24], the expression levels of $L P L$ and FABP4 had significantly down-regulated in breast $(P<0.01)$ compared to those in thigh at 42 and $90 \mathrm{~d}$ in this study. LPL is the rate-limiting step in the hydrolysis of triglyceride from circulating chylomicrons and very low density lipoprotein [25-27]. FABP4 has been considered as a major cytoplasmic protein related to glucose and lipid metabolic functions [28, 29]. These results strongly supported the view of down-regulation of PPARG in breast, revealing that thigh tissue had the stronger lipid biosynthesis compared to breast tissue. 
Cel/ membrane

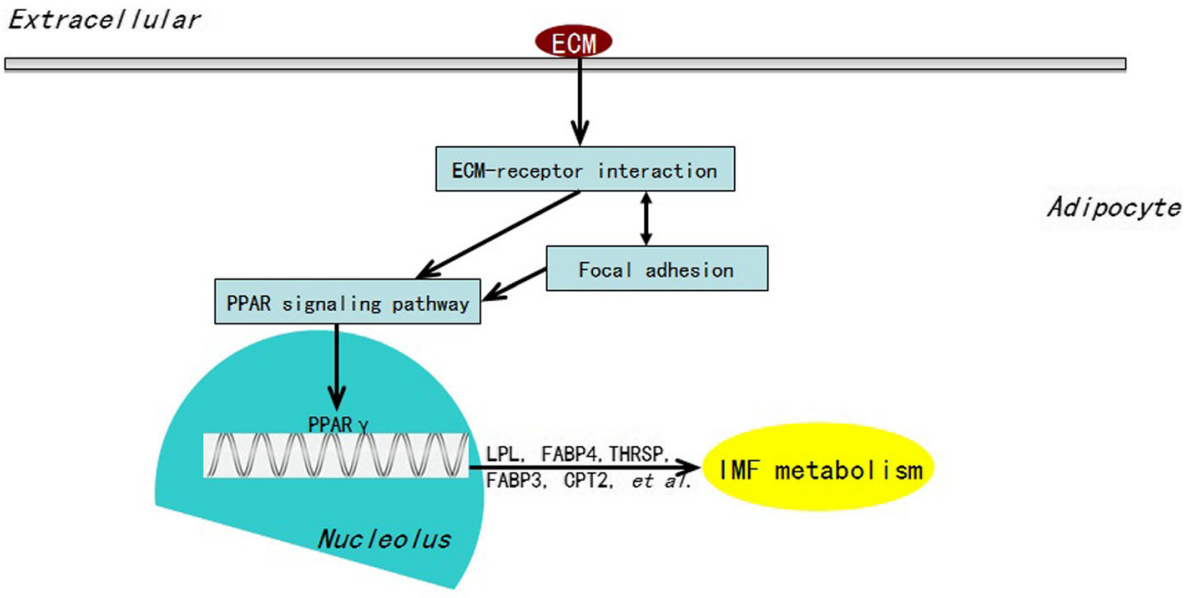

Fig. 6 The potentially regulatory network of IMF metabolism according to DEGs the enriched KEGG pathways. This network is involved in IMF metabolism including PPAR signaling pathway and cell junction (focal adhesion, ECM-receptor interaction)

Similarly, the expression levels of THRSP, RBP7, PLIN and $L D L R$ had significantly down-regulated in breast $(P<0.01)$ than in thigh at 42 and $90 \mathrm{~d}$. As the previous reported, THRSP encodes a small acidic protein that is implicated as a transcription factor involved in control of lipogenic enzymes [30], RBP7 had the important function in regulating the lipid deposition [31], LDLR is a single-chain transmembrane glycoprotein that regulates the plasma cholesterol level [32-34]. So it was revealed that THRSP, PLIN, and LDLR would participate in the regulation of IMF deposition in this study.

On the other hand, FABP3 and CPT2 would participate in the processes of lipolysis process. FABP3 is involved in fatty acid transport from cell membrane to the intracellular sites of fatty acid utilization and is mainly expressed in cardiac and skeletal muscle [35]. CPT2 is one of the two proteins of the carnitine transport system [36], and CPT2 deficiency is an inherited disorder of long-chain fatty acid oxidation $[37,38]$. Their expression levels of these genes had significantly down-regulated in thigh $(P<0.01)$ compared to those in breast at 42 and $90 \mathrm{~d}$. These results revealed that thigh tissue also had the stronger energy supply compared to breast tissue.

The regulation of IMF is possibly a function of complex pathway interactions involving muscle, fat and connective tissue [39]. Combined the data of IMF in breast and thigh tissues, genes related to lipid biosynthesis were dominant than other genes related to lipolysis, and responsible for the more IMF content in thigh tissue.
The pathways of PPAR and cell junctions participated in the regulation of IMF deposition in chicken

KEGG pathway analysis was used to explore the regulatory network underlying chicken IMF deposition. As expected, the well-known PPAR pathway was found. According to the PPAR signaling pathway (gga03320) and the known information, 10 DEGs (PPARG, RXRA, ACSF3, ACSS2, $L P L, C D 36, C P T 2, C Y P 27 A 1, F A B P 3, F A B P 4)$ involved in PPAR signaling pathway here were screened, which have been proven to be functional in lipid metabolism, such as FABP3, FABP4, CD36, LPL.

Of special interest, two pathways (focal adhesions and ECM-receptor interaction) also were enriched, and 5 common known DEGs here were shared by focal adhesions and ECM-receptor interaction. It was revealed that these two pathways had the points for the interaction. Moreover, CAV1 and CD36, which screened as the DEGs in this study, were respectively found in focal adhesions and ECMreceptor interaction. CD36, facilitated the inward transport of fatty acids [40, 41], was involved in ECM-receptor interaction [42, 43]. In support of this, previous studies have shown that changes in cytoskeletal organization and its contacts with the ECM are essential in the morphogenesis of fibroblastic preadipocytes to rounded, mature adipocytes [44]. Caveolins (CAV) are essential components of caveolae, CAV proteins bind cholesterol, and CAV's ability to move between cellular compartments helps control intracellular cholesterol fluxes $[45,46]$.

Taken together, the results revealed that cell junctions (focal adhesions and ECM-receptor interaction) might 
regulate IMF accumulation by associated with the PPAR signaling pathway during chicken development, and the proposed molecular regulatory network affecting IMF metabolism during chicken development is presented in Fig. 6. This is partially consistent with our previous study [14].

\section{Conclusions}

In this study, with the aim of identifying the candidate genes and new pathways related to IMF metabolism for regulatory mechanism between breast and thigh in chicken, it was found that PPARG, LPL, FABP4, THRSP, $R B P 7, P L I N$ and $L D L R$ would be responsible for the IMF deposition in chicken. In addition, IMF deposition in chickens is regulated and mediated not only by genes related to lipid metabolism and PPAR signaling pathway, but also by others involved in cell junctions with the function in maintaining the integrity of tissues and signal transduction.

These findings establish the groundwork and provide new clues for deciphering the molecular mechanisms underlying IMF metabolism in chicken. Further studies at the translational and posttranslational level are now required to validate the genes and pathways identified here.

\section{Methods}

\section{Animals and sample collection}

All 36 Beijing-You chickens (BJY, the Institute of Animal Sciences, Chinese Academy of Agricultural Sciences, Beijing, China) with the same genetic background, entered the experiment at the same time and were randomly distributed into 3 replicate groups, each of 12 birds. Birds were reared in stair-step caging of an environmentally controlled room under continuous lighting using standard conditions of temperature, humidity and ventilation. Feed and water were provided ad libitum during the experiment. Diets were formulated according to Nutrient Requirements of Yellow-feathered Broiler (NY/T 33-2004, China).

At the sampling times of 42 and $90 \mathrm{~d}, 12$ birds with similar weight from each day were selected and killed by stunning and exsanguination after fasting for $12 \mathrm{~h}$. Samples of the pectoralis major muscle (BB) and deboned thigh muscle (BT) were snap frozen in liquid nitrogen and stored at $-80{ }^{\circ} \mathrm{C}$, others were collected and stored at $-20^{\circ} \mathrm{C}$.

\section{Measurement of IMF content}

Two grams of each sample from 12 birds, after eliminating obvious fat, were minced thoroughly after being thawed and dried in two $10-12 \mathrm{~h}$ stages (at $65{ }^{\circ} \mathrm{C}$ and $105{ }^{\circ} \mathrm{C}$, respectively), followed by cooling in a desiccator for at least $30 \mathrm{~min}$. The IMF contents in the pectoralis major muscle and deboned thigh muscle were measured by the Soxhlet method [47, 48], using anhydrous ether as the solvent, and were expressed as percentages, on the basis of dry tissue weight.

\section{RNA extraction and identification}

The tissue samples (breast or thigh) from 6 birds at each day of age, which had the significant difference of IMF between breast tissue or thigh tissue were selected. The total RNA was isolated using the Trizol reagent (Invitrogen, USA) according to the manufacturer's instructions. After the quality verification on gel electrophoresis, A260/A280 and RNA integrity number (RIN), RNA was dissolved with $1 \mu \mathrm{g} / \mu \mathrm{l}$ concentration and six RNA samples from thigh or breast tissues at 42 and $90 \mathrm{~d}$ with equal concentrations were pooled for every microarray analyses.

\section{Microarray hybridization and analysis}

Agilent Gene Chip microarray with 42,034 probe sets (ID: 015068) was finished by Shanghai Biotechnology Corporation (Shanghai, China). Array scanning and data extraction were carried out following the manufacturer's standard protocol.

The normal distribution of signals plot in every chip was provided. Clustering was performed using uncentered Pearson correlations and the average linkage cluster 3.0, and was displayed in TreeView. Normalized fluorescence intensity values of each dye-swapped experiment were averaged separately for sample and reference channels. Thereafter, for each probe, averaged sample and reference fluorescence values were $\log 2$-transformed. Average linkage hierarchical clustering was performed using the Euclidian metric. In the generated heat maps, the colors of the features (probes) were determined by $\log 2$ transformation (sample/reference).

\section{Identification of differentially expressed genes (DEGs)}

The distribution of expressed genes was analyzed by JMP4.0, according to their expression levels. If the flag of a gene was assigned as "P" by the scanner according to the data normalization and Agilent Microarray Suite 4.0 software results, it would be considered as expressed transcripts. The expression value of each probe set was normalized and calibrated using the robust multi-array average (RMA) method.

The data of four groups (42BB, 42BT, 90BB and 90BT) were divided into two comparisons $(42 \mathrm{BB}$ vs $42 \mathrm{BT}$ and $90 \mathrm{BB}$ vs $90 \mathrm{BT}$ ). Differentially expressed probe sets were identified using a cutoff of fold-change $\geq 2.0$ in both comparisons of 42 and $90 \mathrm{~d}$ between thigh and breast tissues. Gene Ontology (GO) enrichment analysis was performed for DEGs related to IMF metabolism at each time point using the GOEAST software toolkit [49]. The significance level of GO term enrichment was set as a false discovery (FDR)-adjusted $p$-value smaller than 0.1, by the Benjamini-Yekutieli method [50]. According to 
the results of GO enrichment analysis, DEGs related to IMF metabolism were screened.

\section{Real-time quantitative PCR (Q-PCR)}

To avoid amplification of contaminating genomic DNA, all primers were placed at or just outside of exon/exon junctions and listed in Additional file 5. Q-PCR was employed using SYBR Green PCR Master Mix (ABI) in the ABI Prism 7500 System under the following conditions: $95{ }^{\circ} \mathrm{C}$ for $10 \mathrm{~min}$ for $1 \mathrm{cycle}$, followed by 40 cycles at $95{ }^{\circ} \mathrm{C}$ for $15 \mathrm{~s}$, and then at $60{ }^{\circ} \mathrm{C}$ for $45 \mathrm{~s}$. Q-PCR was performed in triplicate with standard deviations of threshold cycle $(\mathrm{CT})$ values not exceeding 0.5 .

\section{The Kyoto encyclopedia of genes and genomes (KEGG) pathway analysis}

KEGG pathway [51-53] information was used in this analysis. Probe set IDs of each category were first mapped to NCBI Entrez gene IDs according to the Agilent Chicken Array annotation file, and then mapped to KEGG gene IDs according to the KEGG gene cross-reference file. Pathways that were significantly enriched for DEGs were identified using a hypergeometric test in the R packages $(P<0.1$, FDR adjusted). Pathways with fewer than three known chicken genes were discarded. Graphical pathway maps were downloaded from the KEGG FTP server, and DEGs were then highlighted in them, according to the coordinate description in XML files at the KEGG FTP server, using Perl GD, XML::Parser, and XML::LibXML modules.

\section{Statistical analyses}

Statistical differences between groups were evaluated using the Student's $t$-test. All computations were made using one-way ANOVA and Statistical Analysis Systems software (Version 8.2, SAS Institute, Cary, NC, USA, 2001). $P<0.05\left(^{(*)}\right.$ or $P<0.01\left(^{* *}\right)$ was considered significant. Data are represented as mean $\pm \mathrm{SD}$.

\section{Additional files}

Additional file 1: The DEGs using a cutoff of fold-change $\geq 1.5$ in both comparisons of 42 and $90 \mathrm{~d}$ between thigh and breast tissues. (XLS $154 \mathrm{~kb}$ )

Additional file 2: The biological process of enriched $\mathrm{GO}$ terms based on 515 DEGs. (XLS $516 \mathrm{~kb}$ )

Additional file 3: The DEGs related to lipid metabolism in both comparisons of 42 and $90 \mathrm{~d}$ between thigh and breast tissues. (XLS $55 \mathrm{~kb}$ )

Additional file 4: The common DEGs involved in two pathways (ECM-receptor interaction and Focal adhesion) in this study. (XLS $40 \mathrm{~kb}$ )

Additional file 5: The specific primers for q-PCR in this study. (XLS $57 \mathrm{~kb}$ )

\section{Abbreviations}

ACSF3: Acyl-CoA synthetase family 3; ACSS2: Acyl-CoA synthetase short-chain family member 2; BJY: Beijing-you; C/EBPB: CCAAT/enhancer binding protein beta; CAV: Caveolin; CD36: CD36 molecule; COL: Collagen; CPT2: Carnitine palmitoyltransferase II; DEG: Differentially expressed gene; ECM: Extracellular matrixc; FABP: Fatty acid binding protein; GO: Gene ontology;
IMF: Intramusclar fat; KEGG: Kyoto Encyclopedia of Genes and Genomes; KLF: Kruppel-like transcription factors; LDLR: Low density lipoprotein receptor; LPL: Lipoprotein lipase; PLIN: Perilipin; PPARG: Peroxisome proliferator-activated receptor gamma; PPARGC1A: Peroxisome proliferator activated receptor, gamma, coactivator 1 alpha; Q-PCR: Real-time Quantitative PCR; RBP7: Retinol binding protein 7, cellular; RELN: Reelin; RXRA: Retinoic acid receptor -alpha; SPP1: Secreted phosphoprotein 1); THRSP: Thyroid hormone responsive (SPOT14 homolog)

\section{Acknowledgements}

Not applicable.

\section{Funding}

The research were supported by grants from the National Natural Science Foundation of China (31372305), the Agricultural Science and Technology Innovation Program (ASTIP-IAS04, ASTIP-IAS-TS-11), and the Earmarked Fund for Modern Agro-Industry Technology Research System (CARS-41).

\section{Authors' contributions}

$\mathrm{HC}$ contributed to the design and performing of the study, and writing of the manuscript. MZ and RL contributed to the interpretation of data and writing of the manuscript. JW and GZ designed the study and was in charge of the overall project. All authors read and approved the final manuscript.

\section{Ethics approval and consent to participate}

The animal in this study was conducted in accordance with the Guidelines for the Experimental Animals, established by the Ministry of Science and Technology (Beijing, China). Animal experiments were approved by the Science Research Department (in charge of animal welfare issue) of the Institute of Animal Sciences, CAAS (Beijing, China).

\section{Consent for publication}

Not applicable.

\section{Competing interests}

The authors declare that they have no competing interests.

\section{Publisher's Note}

Springer Nature remains neutral with regard to jurisdictional claims in published maps and institutional affiliations.

Received: 26 February 2017 Accepted: 10 November 2017

Published online: 16 January 2018

\section{References}

1. Haunerland NH, Spener F. Fatty acid-binding proteins-insights from genetic manipulations. Prog Lipid Res. 2004;43(3):328-49.

2. Okeudo NJ, Moss BW. Interrelationships amongst carcass and meat quality characteristics of sheep. Meat Sci. 2005;69(1):1-8

3. Suzuki K, Irie M, Kadowaki H, Shibata T, Kumagai M, Nishida A. Genetic parameter estimates of meat quality traits in Duroc pigs selected for average daily gain, longissimus muscle area, backfat thickness, and intramuscular fat content. J Anim Sci. 2005;83(9):2058-65.

4. Zhao GP, Chen JL, Zheng MQ, Wen J, Zhang Y. Correlated responses to selection for increased intramuscular fat in a Chinese quality chicken line. Poult Sci. 2007;86(11):2309-14.

5. Leveille GA. Vitro hepatic lipogenesis in the hen and chick. Comp Biochem Physiol. 1969;28(1):431-5.

6. Sato K, Akiba Y, Chida Y, Takahashi K. Lipoprotein hydrolysis and fat accumulation in chicken adipose tissues are reduced by chronic administration of lipoprotein lipase monoclonal antibodies. Poult Sci. 1999;78(9):1286-91.

7. Leclercq B. Adipose tissue metabolism and its control in birds. Poult Sci. 1984:63(10):2044-54.

8. Cui HX, Zheng MQ, Liu RR, Zhao GP, Chen JL, Wen J. Liver dominant expression of fatty acid synthase (FAS) gene in two chicken breeds during intramuscular-fat development. Mol Biol Rep. 2012;39(4):3479-84.

9. Lemberger T, Staels B, Saladin R, Desvergne B, Auwerx J, Wahli W. Regulation of the peroxisome proliferator-activated receptor alpha gene by glucocorticoids. J Biol Chem. 1994;269(40):24527-30.

10. Brassant O, Foufelle F, Scotto C, Dauça M, Wahli W. Differential expression of peroxisome proliferator-activated receptors (PPARs): tissue distribution of 
PPAR-alpha, -beta, and -gamma in the adult rat. Endocrinology. 1996; 137(1):354-66.

11. Peters JM, Hennuyer N, Staels B, Fruchart JC, Fievet C, Gonzalez FJ, Auwerx J. Alterations in lipoprotein metabolism in peroxisome proliferator-activated receptor alpha-deficient mice. J Biol Chem. 1997;272(43):273-7.

12. Vanden Heuvel JP. Peroxisome proliferator-activated receptors: a critical link among fatty acids, gene expression and carcinogenesis. J Nutr. 1999;129(2S Suppl):575S-80S

13. Wang HB, Li H, Wang QG, Zhang XY, Wang SZ, Wang YX, Wang XP. Profiling of chicken adipose tissue gene expression by genome array. BMC Genomics. 2007;27(8):193-207.

14. Cui HX, Liu RR, Zhao GP, Zheng MQ, Chen JL, Wen J. Identification of differentially expressed genes and pathways for intramuscular fat deposition in pectoralis major tissues of fast-and slow-growing chickens. BMC Genomics. 2012;13:213-24.

15. Kendziorski C, Irizarry RA, Chen KS, Haag JD, Gould MN. On the utility of pooling biological samples in microarray experiments. Proc Natl Acad Sci U S A. 2005;102(12):4252-7.

16. Akiyama TE, Meinke PT, Berger JP. PPAR ligands: potential therapies for metabolic syndrome. Curr Diab Rep. 2005;5(1):45-52.

17. Berger JP, Akiyama TE, Meinke PT. PPARs: therapeutic targets for metabolic disease. Trends Pharmacol Sci. 2005;26(5):244-51.

18. Ahmed W, Ziouzenkova O, Brown J, Devchand P, Francis S, Kadakia M, Kanda T, Orasanu G, Sharlach M, Zandbergen F, Plutzky J. PPARs and their metabolic modulation: new mechanisms for transcriptional regulation? J Intern Med. 2007;262(2):184-98.

19. Handschin C, Spiegelman BM. Peroxisome proliferator-activated receptor gamma coactivator 1 coactivators, energy homeostasis, and metabolism. Endocr Rev. 2006;27(7):728-35.

20. Gerhart-Hines Z, Rodgers JT, Bare O, Lerin C, Kim SH, Mostoslavsky R, Alt FW, Wu Z, Puigserver P. Metabolic control of muscle mitochondrial function and fatty acid oxidation through SIRT1/PGC-1alpha. EMBO J. 2007;26(7):1913-23.

21. Kim JH, Park KW, Lee EW, Jang WS, Seo J, Shin S, Hwang KA, Song J. Suppression of PPARy through MKRNI-mediated ubiquitination and degradation prevents adipocyte differentiation. Cell Death Differ. 2014;21(4):594-603.

22. Qi C, Zhu Y, Reddy JK. Peroxisome proliferator-activated receptors, coactivators, and downstream targets. Cell Biochem Biophys. 2000;32 Spring:187-204.

23. Zhang ZW, Rong EG, Shi MX, CY W, Sun B, Wang YX, Wang N, Li H. Expression and functional analysis of Krüppel-like factor 2 in chicken adipose tissue. J Anim Sci. 2014;92(11):4797-805.

24. Martin G, Schoonjans K, Staels B, Auwerx J: PPAR gamma activators improve glucose homeostasis by stimulating fatty acid uptake in the adipocytes. Atherosclerosis 1998, 137Suppl:S75-S80.

25. Bensadoun A. Lipoprotein lipase. Annu Rev Nutr. 1991;11:217-37.

26. Goldberg IJ. Lipoprotein lipase and lipolysis: central roles in lipoprotein metabolism and atherogenesis. J Lipid Res. 1996;37(4):693-707.

27. Olivecrona G, Olivecrona T. Triglyceride lipases and atherosclerosis. Curr Opin Lipidol. 1995:6(5):291-305.

28. Cao H, Gerhold K, Mayers JR, Wiest MM, Watkins SM, Hotamisligil GS. Identification of a lipokine, a lipid hormone linking adipose tissue to systemic metabolism. Cell. 2008;134(6):933-44.

29. Makowski L, Brittingham KC, Reynolds JM, Suttles J, Hotamisligil GS. The fatty acid-binding protein, aP2, coordinates macrophage cholesterol trafficking and inflammatory activity. Macrophage expression of aP2 impacts peroxisome proliferator-activated receptor gamma and IkappaB kinase activities. J Biol Chem. 2005;280(13):12888-95.

30. Liaw CW, Towle HC. Characterization of a thyroid hormone-responsive gene from rat. J Biol Chem. 1984:259(11):7253-60.

31. Ahn J, Shin S, Suh Y, Park JY, Hwang S, Lee K. Identification of the avian RBP7 gene as a new adipose-specific gene and RBP7 promoter-driven GFP expression in adipose tissue of transgenic quail. PLoS One. 2015;10(4):e0124768.

32. Goldstein JL, Brown MS, Anderson RG, Russell DW, Schneider WJ. Receptormediated endocytosis: concepts emerging from the LDL receptor system. Annu Rev Cell Biol. 1985;1:1-39.

33. Brown MS, Goldstein JL. A receptor-mediated pathway for cholesterol homeostasis. Science. 1986;232(4746):34-47.

34. Hobbs HH, Brown MS, Goldstein JL. Molecular genetics of the LDL receptor gene in familial hypercholesterolemia. Hum Mutat. 1992;1 (6):445-66.

35. Veerkamp JH, Maatman RG. Cytoplasmic fatty acid-binding proteins: their structure and genes. Prog Lipid Res. 1995;34(1):17-52.
36. Finocchiaro G, Taroni F, Rocchi M, Martin AL, Colombo I, Tarelli GT, DiDonato S. cDNA cloning, sequence analysis, and chromosomal localisation of the gene for human carnitine palmitoyltransferase. Proc Natl Acad Sci U S A. 1991;88(2): 661-5.

37. Bonnefont JP, Demaugre F, Prip-Buus C, Saudubray JM, Brivet M, Abadi N, Thuillier L. Carnitine palmitoyltransferase deficiencies. Mol Genet Metab. 1999;68(4):424-40

38. Wieser T, Deschauer M, Olek K, Hermann T, Zierz S. Carnitine palmitoyltransferase II deficiency: molecular and biochemical analysis of 32 patients. Neurology. 2003; 60(8):1351-3.

39. Hocquette JF, Gondret F, Baéza E, Médale F, Jurie C, Pethick DW. Intramuscular fat content in meat-producing animals: development, genetic and nutritional control, and identification of putative markers. Animal. 2010;4(2):303-19.

40. Hajri T, Abumrad NA. Fatty acid transport across membranes: relevance to nutrition and metabolic pathology. Annu Rev Nutr. 2002:22:383-415.

41. Ibrahimi A, Abumrad NA. Role of CD36 in membrane transport of long-chain fatty acids. Curr Opin Clin Nutr Metab Care. 2002;5(2):139-45.

42. Bornstein P. Diversity of function is inherent in matricellular proteins: an appraisal of thrombospondin 1. J Cell Biol. 1995;130(3):503-6.

43. Febbraio M, Silverstein RL. CD36: implications in cardiovascular disease. Int J Biochem Cell Biol. 2007;39(11):2012-30.

44. Kawaguchi N, Sundberg C, Kveiborg M, Kveiborg M, Moghadaszadeh B, Asmar M, Dietrich N, Thodeti CK, Nielsen FC, Möller P, Mercurio AM, Albrechtsen R, Wewer UM. ADAM12 induces actin cytoskeleton and extracellular matrix reorganization during early adipocyte differentiation by regulating beta1 integrin function. J Cell Sci. 2003:116(19):3893-904.

45. Parton RG, Simons K. The multiple faces of caveolae. Nat Rev Mol Cell Biol. 200;8(3):185-94

46. Pol A, Martin S, Fernández MA, Ingelmo-Torres M, Ferguson C, Enrich C, Parton RG. Cholesterol and fatty acids regulate dynamic caveolin trafficking through the Golgi complex and between the cell surface and lipid bodies. Mol Biol Cell. 2005;16(4):2091-105.

47. AOAC. Official methods of analysis: fat or ether extract in meat. 15th ed. Assoc. Off. Anal. Chem., Washington, DC. 1990

48. Zerehdaran S, Vereijken AL, van Arendonk JA, van der Waaijt EH. Estimation of genetic parameters for fat deposition and carcass trait in broilers. Poult Sci. 2004;83(4):521-5.

49. Zheng Q, Wang XJ. GOEAST: a web-based software toolkit for gene ontology enrichment analysis. Nucleic Acids Res. 2008;36(Web Server issue):W358-63.

50. Benjamini Y, Yekutieli D. The control of the false discovery rate in multiple testing under dependency. Ann Stat. 2001;29:1165-88.

51. Kanehisa M, Araki M, Goto S, Hattori M, Hirakawa M, Itoh M, Katayama T, Kawashima S, Okuda S, Tokimatsu T, Yamanishi Y. KEGG for linking genomes to life and the environment. Nucleic Acids Res. 2008:36(Database issue):D480-4

52. Kanehisa M, Goto S. KEGG: kyoto encyclopedia of genes and genomes. Nucleic Acids Res. 2000;28(1):27-30

53. Kanehisa M, Goto S, Hattori M, Aoki-Kinoshita KF, Itoh M, Kawashima S, Katayama T, Araki M, Hirakawa M. From genomics to chemical genomics: new developments in KEGG. Nucleic Acids Res. 2006;34(Database issue):D354-7.

\section{Submit your next manuscript to BioMed Central and we will help you at every step:}

- We accept pre-submission inquiries

- Our selector tool helps you to find the most relevant journal

- We provide round the clock customer support

- Convenient online submission

- Thorough peer review

- Inclusion in PubMed and all major indexing services

- Maximum visibility for your research

Submit your manuscript at www.biomedcentral.com/submit
) Biomed Central 